\title{
A ESCOLA COMO TEMPO/ESPAÇO DE RESISTÊNCIA E SUPERAÇÃO DAS DESIGUALDADES: A RELAÇÃO COM OS TERRITÓRIOS
}

\author{
DuCINÉA CAMPOS \\ Itamar Mendes da Silva \\ Universidade Federal do Espírito Santo (UFES), Espírito Santo, Vitória, \\ Brasil \\ Caroline Falco Fernandes Valpassos \\ Universidade de Brasília (UnB), Brasília, Distrito Federal, Brasil
}

\begin{abstract}
Resumo: Este artigo especifica as análises e discussões desenvolvidas so bre a temática Escola: espaços e tempos de reprodução e resistências da pobreza, com foco na relação da escola com o seu território, realizadas com o objetivo de identificar como a escola se relaciona com os seus territórios empobrecidos e analisar as implicações dessa relação para a produção de resistência e da superação da pobreza. Para tanto, adotou-se a pesquisa qualitativa baseando-se no método dialético. Este estudo evidenciou, por fim, que as escolas não desenvolvem uma relação efetiva com os seus territórios no sentido de reconhecê-los como espaços importantes de aprendizagem e de produção de vida.
\end{abstract}

Palavras-chave: Território. Pobreza. Educação emancipatória. Escola.

\section{INTRODUÇÃO}

Este artigo apresenta parte das discussões produzidas em uma pesquisa intitulada Políticas e Práticas de Educação, Pobreza e Desigualdade Social no Espírito Santo desenvolvida durante a realização do Curso de Especialização em Educação, Pobreza e Desigualdade Social (EPDS/SECADI/MEC, 2015-2017), da Universidade Federal do Espírito Santo (UFES). Trata-se de um curso de pós-graduação lato sensu, que objetivou formar professores, gestores da educação básica e outros profissionais envolvidos (as) com políticas sociais de combate à pobreza nos contextos socioculturais empobrecidos, assumindo como princípio orientador a vida digna que é um direito de todos os seres humanos e não deve se restringir a uma minoria da população.

Com essa perspectiva, o curso foi realizado de forma semipresencial, com a utilização dos instrumentos tecnológicos da metodologia em Educação a Distância (Ead) e com o desenvolvimento de um programa instrucional em forma de módulos. As 
atividades realizadas tiveram por base a dialética entre a ação-reflexão-ação que, após realizadas pelos cursistas, eram registradas em relatórios, por meio dos quais reunimos os elementos para as análises. No processo de organização dos dados, foi utilizado o software Atlas T.I. (programa usado principalmente, mas não exclusivamente, em pesquisa qualitativa ou análise de dados qualitativos). No Atlas T.I., adicionamos as atividades de reflexão-ação na caixa do gerenciador principal ("Primarydoc manager") separadas por polos e regiões, com estabelecimento de códigos (codes). A partir dos códigos, foram criadas famílias (families) que produziram excertos com base nas linhas de análises definidas no projeto de pesquisa. As marcações que aparecem entre parênteses, no final de cada excerto citado neste artigo, representam as referências dos documentos organizados segundo critérios do Programa Atlas T.I.

Neste artigo, ap resentamos as análises e discussões das atividades desenvolvidas sob a temática escola: espaços e tempos de reprodução e resistências da pobreza, com foco na relação da escola com o seu território. Interessou-nos saber como a escola dialoga com os seus territórios empobrecidos e quais as consequências para a produção de resistência e da superação da pobreza. As análises das fontes foram realizadas por meio das bases epistemológicas fornecidas pelo método dialético que nos impeliu a apreender as relações sociais e históricas, compreendendo as contradições e a realidade em sua totalidade, em sua especificidade e em sua singularidade, por meio das diferenciadas formas com que se apresentam os fenômenos no decorrer das análises. Focamos neste estudo os fenômenos da vida social, reconhecendo a sua historicidade e, ao mesmo tempo, que eles não são naturais e tampouco imutáveis.

A partir dessas considerações introdutórias, este artigo segue com as análises das enunciações das famílias beneficiárias do PBF para compreender as suas expectativas em relação à educação de seus filhos. Com narrativas reflexivas sobre o mundo da escola e o mundo do território com ênfase nas relações estabelecidas pela escola, adotamos, como critério de análise, as seguintes categorias: 1) a relação com os movimentos sociais; 2) a relação por meio de programas institucionais; e 3) os empecilhos apontados pela escola como fatores impeditivos para a efetivação dessa relação. Por último, tecemos as considerações finais.

\section{AS EXPECTATIVAS DAS FAMÍLIAS EM RELAÇÃO À EDUCAÇÃO: AS ENUNCIAÇÕES DOS SUJ EITOS A PARTIR DE SUAS EXISTEENCIAS}

O Programa Bolsa Família, criado em 2003, tem como objetivo aumentar a renda familiar de pessoas de baixa e baixíssima renda. Para que as famílias sejam beneficiadas, elas são submetidas a algumas condicionalidades, entre elas, encontra-se a obrigatoriedade da frequência escolar. 0 cumprimento das condicionalidades possibilitou maior aproximação das famílias beneficiárias com a escola, gerando sobre elas expectativas de que a educação seria o passaporte para uma vida livre da pobreza. Isso ficou evidente nos relatos dos pais no decorrer das entrevistas realizadas, buscando saber as suas expectativas em relação à educação para a vida de seus filhos. Para essa discussão, trazemos o recorte das entrevistas realizadas com as famílias beneficiárias do PBF sobre o que elas esperam da educação: 
A educação é uma oportunidade de se ter uma vida confortável, porque sem estudo ninguém é nada (P56).

Com a educação pode ter uma profissão e ser alguém na vida (P478).

Os meus filhos tenham um futuro melhor, diferente do que eu tive. É um privilégio que não se pode comparar (P469).

Possuir seu próprio pedaço de terra para poder plantar o que quiser, não ter que dividir com o patrão (P77).

Minha esperança é que meus filhos se formem nos estudos e consigam um trabalho assalariado para ter uma vida melhor (P77).

Os enunciados dos pais apresentam uma única linha de raciocínio, até porque todos eles consideram a edu cação muito importante, uma esperança, um privilégio e uma oportunidade que os pobres devem aproveitar para "ser alguém na vida". Os relatos evidenciam que os pais veem a oferta de educação como privilégio e por isso os seus filhos não terão a mesma sorte que eles. Freire (2011) relaciona essa ausência de compreensão dos determinantes so ciais da pobreza e da educação como direito negado, com uma visão fatalista e reducionista da pobreza que a naturaliza e a considera inerente a uma determinada classe social. Contrariando essa visão, o autor convoca os educadores a concentrar suas atenções nos efeitos desumanizad ores da pobreza bem como a envidar esforços em prol de uma educação emancipadora, capaz de auxiliar essas pessoas, que vivem em situações-limite e desumanizadoras, a se perceberem como sujeitos de mudança, capazes de enxergar, no contexto em que vivem, as intensas contradições sociais e, assim, vislumbrar possibilidades de superação.

A educação para essas famílias é a única possibilidade para a superação da pobreza. Portanto, por meio da educação é que elas poderão ser "alguém na vida". O "não alguém" está associado à sua condição de classe social discriminada, pois sabem que vivem em posições inferiorizadas a uma classe social mais elevada. Quanto a essa questão, Paulo Freire (2005) esclarece que os vários grupos que diferem da classe dominante, além de serem os alijados de direitos sociais básicos, são também considerados inferiores. São pessoas que discrepam da fisionomia geral da sociedade que, de acordo com o parâmetro social, é boa, organizada e justa. Com esse parâmetro socialmente construído pela classe dominante, essas pessoas ainda não se consideram "alguém", ou melhor, não como aquelas favorecidas socialmente.

Assim, os dizeres dos sujeitos, a partir dos seus territórios, convocam a escola a exercer o papel de intermediadora dessa realidade, desenvolvendo, por conseguinte, uma educação adequada às necessidades das pessoas. Nesse sentido, Arroyo (2003) também é enfático ao afirmar que cabe à escola se apresentar como um direito, e não como uma dádiva política. Por isso, ela deve sempre se colocar na fronteira do conjunto dos direitos humanos. Ao se colocar no campo do direito, a escola cumpre um importante papel de ajudar os estudantes a decifrar os enigmas do mundo, sobretudo, o do estranhamento de um mundo produzido pelos próprios homens (MÉSZÁROS, 2005). Dentre esses enigmas, encontram-se os fatores determinantes da pobreza.

Destremau e Salama (1999) afirmam que o conceito de pobreza é complexo e multidimensional. Dessa forma, conhecê-lo apenas no plano teórico não nos capacita compreender efetivamente a pobreza em suas expressões na vida das pessoas. Com base 
nesse conceito, o empobrecido não é facilmente definido, porque as suas diferentes facetas estão relacionadas com a realidade concreta da vida das pessoas. Portanto, a identificação das diferentes facetas da pobreza não pode ocorrer descolada dos contextos de vida dos sujeitos. Desse modo, nos dizeres recorrentes das famílias que consideram a escola uma dádiva política e reconhecem a educação como única forma capaz de resolver as condições de pobreza das próximas gerações, outras questões, que atravessam a pobreza, não são percebidas.

Segundo Arroyo (2016), há fatores que se repetem na definição das características da maioria dos pobres (gênero, etnia, de onde vêm, onde vivem); e se são mulheres, são negros, são indígenas, são do campo, são favelados. Nesse sentido, 0 autor indaga: o que a escola sabe desses sujeitos pobres? Será que a escola tem clareza da expectativa desses sujeitos sobre a educação? Que educação é ou deveria ser oferecida a eles?

Nas vozes dessas famílias se encontra a reprodução da concepção de educação que orienta muitos programas sociais que consideram 0 acesso à educação como redenção, capaz de combater a pobreza e a desigualdade social. A educação como redenção - e como condicionalidade - segue a lógica da concepção da Organização das Nações Unidas para a Educação, a Ciência e a Cultura (Unesco), pela qual é entendida como um caminho para se conseguir um desenvolvimento humano com menos pobreza, sem exclusão aos direitos, discriminação e opressão (YANNOULAS, 2013). Essa autora, apesar de reconhecer que a educação não tem o poder de superação da pobreza, defende a sua importância nos processos de luta e transformação social. No entanto, analisa criticamente que essas políticas colocam sobre os indivíduos a responsabilidade pela superação da pobreza e não é por acaso que elas definiram o critério da condicionalidade para receber o recurso Bolsa Família (BF), visto que, para muitas dessas famílias, esse recurso significa a possibilidade de continuar sobrevivendo.

Uma contradição importante emerge nos/dos discursos dos sujeitos, como o caso de um pai, cuja família reside e trabalha em uma fazenda, que relata, com resignação, a dor sentida ao ver os seus filhos viverem em situação precária. Não tendo comida em casa, eles precisam ir à escola para se alimentarem: "Mas, mesmo assim, fico feliz porque vão ser diferente de mim [...]" (P440). Essa família, além de ver a escola como uma opção para matar a fome dos filhos, considera-a também como uma possibilidade de superação e melhoria de suas condições de vida. Chamamos atenção para o fato de essa família morar e trabalhar em fazenda, ou seja, mora em cima da terra e não a utiliza para prover o seu sustento básico que é o alimento. Essa contradição social é promovida por um modelo econômico capitalista fundado no latifúndio e na monocultura, o qual transforma o homem do campo em empregado, tirando dele e da terra a sua principal função que é prover alimentos para si e para os outros. A ocupação do solo, a distribuição da terra e a produção de alimentos se configuram como uma importante questão social de combate à pobreza que atinge 0 campo e a cidade. Desse modo, o combate à pobreza dos povos do campo e da cidade merece destaque nos currículos escolares.

Outra enunciação, também de famílias que vivem no campo, considera a educação fundamental, mas elas se situam historicamente, demonstrando ter mais compreensão das contradições sociais em que estão envolvidas e as que são submetidas. 
Elas sabem, portanto, que a educação é um direito fundante, mas apontam outras questões que também são igualmente importantes, como políticas de distribuição de renda para as pessoas do campo. Compreendem que a reforma agrária é a forma principal de distribuição de renda da classe trabalhadora, por meio da conquista da terra para nela produzir, pois "possuir seu próprio pedaço de terra para poder plantar o que quiser, não ter que dividir com o patrão e ainda poder contar com a ajuda da esposa e dos filhos à medida que forem crescendo, sem, contudo, abandonar os estudos" (P77). A partir disso, elas também reconhecem que a educação qualifica o trabalho no campo por meio de conhecimentos científicos que melhoram a tecnologia e a preservação do meio ambiente, mas é necessário aliar a esse processo educativo o engajamento social de que Ihe é próprio.

Nessa mesma perspectiva, outro pai, morador do campo, assinalou que a situação poderia ser melhorada:

[...] com uma reforma agrária, onde o trabalhador rural pudesse ter seu próprio pedaço de terra para produzir, com apoio e incentivo do estado, como: assistência técnica e financiamento para o cultivo de alimentos de subsistência e para comercialização, ou seja, a policultura melhoraria toda situação da região que, de uns tempos para cá, se transformou em monocultura, uma vez que as pequenas propriedades de agricultura familiar foram desaparecendo, dando lugar a grandes propriedades onde predomina a monocultura, geralmente de café, e com isso praticamente todos os gêneros alimentícios têm que ser comprados. Não há lugar para plantar sequer um pé de mandioca, algo inimaginável até há pouco tempo, famílias que trabalham na terra, tendo que comprar aipim, inhame, batata doce, enfim, produtos que poderiam ser colhidos com facilidade e melhorariam muito a alimentação dessa população. É claro que vendendo o excedente de suas colheitas sua situação financeira ficaria equilibrada garantindo um padrão de vida confortável (P90).

A fala acima é de quem compreende a sua condição de pobreza como historicamente produzida pelo modelo político e econômico praticado no país. Denuncia o modelo agrícola capitalista que concentra grandes dimensões de terra nas mãos de poucos, mas reconhece que, por meio de suas ações coletivas, vinculadas a movimentos sociais, elas podem se contrapor a esse modelo, propondo e exigindo ações dos governos contra a pobreza e as desigualdades. Esses movimentos sociais definem como a educação pode contribuir com as conquistas dos cidadãos e também a relação que a escola pode estabelecer com as famílias que pertencem a um coletivo empobrecido. Eles se constituem como espaços coletivos, visando a ações de soluções para superação dos problemas sociais detectados. Assim, o campo torna-se um território de produção de história e cultura, de luta de resistência dos sujeitos que ali vivem.

Nessa perspectiva, cabe à escola, que atende aos sujeitos do campo, indagar: 
Quem são os sujeitos do campo? Como se formam/se educam nos diferentes espaços onde desenvolvem sua experiência humana: na família, no trabalho, nas relações comunitárias, na escola, no movimento social? Quem são e como se educam as crianças, os jovens, os adultos, os idosos do campo? Como se constituem a infância, a juventude, a idade adulta e a velhice no campo? E quem são e como se formam os educadores dos sujeitos do campo? Que processos formadores vivenciam na própria ação de educar? (CALDART, 2006, p. 12).

Essas respostas são encontradas, portanto, nos conhecimentos produzidos no contexto das práticas sociais dos sujeitos em seus territórios. Dessa forma, somente no diálogo entre escolas e seus respectivos territórios a troca de saberes pode se efetivar objetivamente. Nesse sentido, a escola há de estabelecer relação permanente com o seu entorno, conhecendo os seus diversos agentes formativos, suas demandas e suas lutas para que haja uma democratização dos saberes no âmbito escolar. A pobreza no campo é diferente da pobreza da cidade. Campo e cidade são territórios diferentes que possuem suas próprias especificidades. Logo, compreender essas especificidades é fundamental para se entender que, nessas especificidades, há produções de vida que precisam ser consideradas no processo educativo. Nesse sentido, a relação escola e território é imprescindível para a organização do trabalho pedagógico em sintonia com as necessidades dos sujeitos empobrecidos, constituindo-se, com isso, um importante espaço/tempo de resistência e combate à pobreza.

\section{AS RELAÇÕES ESCOLA E COMUNIDADE/TERRITÓRIOS: UMA RESPONSABILIDADE SOCIAL}

Com Santos (1978), refletimos que "espaço geográfico" e "território" são indissociáveis, visto que a utilização do território pelo povo é que cria o espaço. Nesses espaços, portanto, o homem realiza a sua vida e, nessa direção, é importante que ele seja compreendido a partir da relação de poder de que o atinge, ou seja, a mesma contradição existente no processo produtivo, com subordinados e subordinantes, existe também nesses espaços. Eles não são indissociáveis. É um espaço contraditório, pois, ao mesmo tempo que congrega as pessoas em torno do processo produtivo, também as divide por esse mesmo processo. O território, por sua vez, é um espaço de produção de vida, de diversidade, de culturas, de trabalho etc. Nesse sentido, o espaço geográfico é formado por um conjunto integrado, solidário e também contraditório, visto que ele não está desvinculado das contradições existentes na sociedade capitalista. O espaço é uma totalidade, a exemplo da própria sociedade que lhe dá vida: "[...] o espaço se define como um conjunto de formas representativas de relações sociais do passado e do presente e por uma estrutura representada por relações sociais que se manifestam através de processos e funções" (SANTOS, 1978, p. 122).

Para Santos (1978), os espaços são criados de acordo com a forma como eles são ocupados pelo povo. Desse modo, o território existe antes do espaço, portanto a escola que se encontra dentro desse território também contribui na criação desse espaço, pois, segundo o autor, no território, além da natureza, há sentimentos, há história, há produção 
de conhecimentos, há construção de formas de produção de vidas. Tudo isso constitui a identidade dos sujeitos que ocupam os espaços escolares.

A escola também é um espaço que possui suas próprias normas que, por vezes, se diferenciam das práticas sociais dos estudantes. Nesse sentido, há o mundo da escola e o mundo do território que também são, ou deveriam ser, indissociáveis. Esse tópico parte do princípio de que a escola não detém o monopólio da educação, uma vez que ela ocorre em diferentes espaços sociais, como no trabalho, na família, na igreja, nas rodas de viola, nas lutas pela sobrevivência, nos movimentos sociais etc. Nessa perspectiva, a educação não é, então, sinônimo de escola, visto que, nas práticas sociais dos muitos coletivos, ocorrem processos (de) formativos com a produção de diferentes saberes em diferentes dimensões.

De acordo com as observações dos cursistas, foi possível analisar as formas como as escolas se relacionam com os seus territórios, partindo do princípio de que ambos são espaços educativos e que devem estar em permanente interação. Há currículo na escola, mas há também currículo fora dela com possibilidades variadas. Nos excertos analisados, são várias as formas que a escola encontra para se relacionar com o território em que está inserida. Agrupamos os dados comuns nas seguintes categorias: 1) compartilhamento de espaços; 2) movimentos sociais; 3) formas de participação: 4) programas institucionais; $\mathrm{e}$ 5) empecilhos apontados.

\section{RELAÇÃO ESCOLA E TERRITÓRIO: COMPATILHAMENTO DE ESPAÇOS FÍSICOS}

A escola, quer queira, quer ou não, está situada em um território e são várias as formas de integração entre o espaço escolar e o território. Uma delas é pelo fato de compartilharem os seus espaços físicos. A comunidade cede os seus espaços para a escola desenvolver os seus projetos e participa dos eventos como convidada e espectadora: "Os espaços dispostos na comunidade são aproveitad os pela escola, muitas vezes em projetos motivados por professo res ou equipe gestora de forma a garantir um entrosamento entre alunos, professores, pais e comunidade local" (P4). Nesse caso, a relação que se estabelece entre ambos consiste apenas na cessão do local, mas a organização das ações é de responsabilidade da escola somente. Não há uma relação que se transforme em processo educativo e de oportunidades de aprendizagens.

A escola, além disso, também disponibiliza os seus espaços para serem utilizados fora de seus horários de aula, como espaço de recreação para a comunidade, conforme a enunciação que segue: "É disponibilizado o espaço na escola, nos fins de semana e no período de férias, para realização de atividades que atendam à comunidade" (P54). Há casos em que, mesmo a escola não autorizando, a comunidade ocupa seus espaços mesmo assim: "Os moradores do bairro utilizam a quadra pela noite, invadindo-a ou combinando com o vigia noturno" (P20). A ocupação da comunidade, classificada nas falas dos sujeitos por "invasão" ou "burla", revela a ausência de diálogo entre a escola e a comunidade e vice-versa. É como se a escola não Ihes pertencesse, não fizesse parte de suas identidades e de suas histórias. A escola, fisicamente, coloca-se para a comunidade como um espaço que não lhe pertence. Isso, por vezes, é verificado a partir de sua própria estrutura física. Os seus muros são demasiadamente altos, os portões cheios de cadeados, portas e janelas gradeadas e é administrada com normas rígidas de funcionamento, 
contribuindo com o distanciamento entre os dois tempos e os espaços educativos.

Há também situações em que a escola cede 0 espaço apenas para desenvolvimento de projetos da comunidade: "A quadra da escola é cedida para a realização do projeto, de forma a não atrapalhar as aulas curriculares da disciplina de Educação Física" (P93). De qualquer modo, a utilização dos espaços ocorre como forma de empréstimo e não como objetivo de participação e de construção de novas relações sociais. Há uma ponderação de uma cursista assinalando que: "Mesmo tendo mecanismos, como o Conselho de Escola, reunião de pais, eventos culturais dos quais a comunidade participa, cabe ressaltar que os espaços educativos, para além dos muros da escola são poucos utilizados" (P225).

Há, porém, relatos de experiência que destoam do que foi até então apresentado. Trata-se de uma escola que é o único ponto de encontro e confraternização no território e ele é partilhado: "Como única instituição pública no bairro que surgiu como um marco na vida dos moradores. Este foi o espaço que encontraram para realização de suas festas e eventos: casamentos, aniversários e até para encontros religiosos" (P112). Mesmo assim, não percebemos a participação da comunidade na organização didático-pedagógica e administrativa da escola.

\section{RELAÇÃO ESCOLA E TERRITÓRIO: MOVIMENTOS SOCIAIS}

Os movimentos sociais atuam no campo dos direitos negados e suas ações são associadas, entre outras questões: ao direito de propriedade, mediante ocupações de terra, de moradia, de empresa; à igualdade formal que tenta desconsiderar as diferenças de ordem material, de gênero, de etnia etc.; ao direito de ir e vir; e à dilapidação do meio ambiente. Eles desenvolvem, portanto, processos de lutas sociais que visam a melhorias das condições existentes na realidade concreta. Nesses espaços de lutas, há toda uma produção de conhecimento e de organicidade que só é compreendida a partir das interações que se constituem no processo participativo.

$\mathrm{Na}$ análise dos materiais, encontramos apenas uma menção aos movimentos sociais que se refere aos Movimentos dos Trabalhadores Rurais Sem-Terra (MST). A citação a seguir expressa uma das lutas do MST, que é a busca pelo direito de seus filhos estudarem em suas próprias comunidades, ou melhor, no campo:

Esta continuidade dos estudos dos filhos de Assentados foi mais uma conquista de muita luta e persistência de algumas famílias e Setor de Educação do MST. Era o desejo de muitos pais que queriam que desse continuidade aos estudos de seus filhos e que fosse no próprio assentamento, uma vez que no mesmo só atendia de 1 à a 4a série (P62).

A partir do explicitado, é importante apresentarmos a caracterização desse movimento. Para isso, recorremos a Fernandes (2012.p. 456), pois, para ele, o MST tratarse de: 
[...] um movimento socioterritorial que reúne em sua base diferentes categorias de camponeses pobres - como parceiros, meeiros, posseiros, minifundiários e trabalhadores assalariados chamados de sem-terra - e também diversos lutadores sociais para desenvolver as lutas pela terra, pela Reforma Agrária e por mudanças na agricultura brasileira.

Dentre as suas lutas, encontra-se a educação pública como direito dos cidadãos e dever do estado. Eles defendem o direito à educação básica no território onde vivem e por isso só reconhecem o currículo desde que ele privilegie os conhecimentos escolares articulados com as suas realidades e seus modos de vida, por meio de uma concepção de conhecimento que os ajudem a compreender a realidade local, relacionando-a com a realidade do Brasil e do mundo.

Nos relatos das famílias, há evidências de movimentos sociais nos territórios escolares. No entanto, observamos um silenciamento nos relatórios da existência de qualquer forma de relação ou mesmo de reconhecimento por essas instituições educativas de suas existências, movimentos sociais nos territórios das escolas e da pouca menção de indicativos da relação da escola com eles. Cabe, então, a cada escola se perguntar quais são os movimentos sociais existentes em seus respectivos territórios, quais as suas lutas, como se organizam e como proceder no diálogo entre esses dois espaços formativos: escola e movimentos sociais. Contudo, não basta saber da existência dos movimentos sociais, é preciso aprender com eles. Arroyo (2003) não teme supor que as mobilizações dos movimentos so ciais agem de forma pedagógica no aprendizado dos direitos sociais, especificamente, do direito à educação:

Essa pedagogia que pode ser encontrada nas lutas e mobilizações dos setores populares das cidades e dos campos se encontra com o aprendizado dos direitos vindo da inserção no trabalho. [...] A consciência do direito ao trabalho e à cidade $\mathrm{e}$ à terra se alimentam e contaminam. A consciência dos direitos se radicaliza na inserção na produção e se amplia nas lutas pela inserção nos serviços básicos para a reprodução digna da existência (ARROYO, 2003, p. 30).

São processos formativos não escolares que tiveram e continuam tendo um papel pedagógico relevante na formação de coletivos sociais nas camadas populares e, nessa direção, é fundamental indagar, tendo em vista a construção de uma proposta pedagógica articulada à vida, sobre as “[...] matrizes pedagógicas ou sobre as dimensões da teoria pedagógica em que os movimentos sociais se encontram ou desencontram com a educação formal e informal, sobre as marcas que eles deixam na formação dos atores sociais" (ARROYO, 2003, p. 33). De acordo com o autor, os coletivos que compõem os movimentos sociais são de todas as idades, gêneros e raças. Tanto as crianças, adolescentes e mulheres entram em movimento, expõem-se, vivenciam o risco, a repressão, a morte, frequentemente. Ou seja, todos vivenciam as mesmas situaçõeslimite: “Essas crianças e esses adolescentes, jovens ou adultos que experimentam esse tenso limiar carregam para as experiências de educação formal ou informal suas vivências e aprendizados. 0 que fazer, ignorá-los ou incorporá-los?" (ARROYO, 2003, p. 37).

RELAÇÃO ESCOLA E TERRITÓRIO: PROGRAMAS INSTITUCIONAIS 
Nos relatórios, foram muitas as ações desenvolvidas pela escola para além do muro escolar que apresentam relação direta com programas institucionais do Governo Federal e Estadual, tais como: Mais Educação, Escola Aberta e o Programa Educacional de Resistência às Drogas (Proerd). No geral, os alunos saem da escola para ter aulas em outros espaços e realizar excursões com função e cobranças pedagógicas e avaliativas.

O programa Mais Educação, segundo a cartilha Passo a Passo do MEC, foi instituído pela Portaria Interministerial n.. 17/2007 e integra as ações do Plano de Desenvolvimento da Educação (PDE), como uma estratégia do Governo Federal para induzir a ampliação da jornada escolar e a organização curricular, na perspectiva da Educação Integral. É um programa que atende, prioritariamente, escolas de baixo Índice de Desenvolvimento da Educação Básica (Ideb), situadas no campo e na cidade, especialmente em territórios de grande índice de pessoas empobrecidas. De acordo com os relatórios, são vários os projetos desenvolvidos pela escola como:

Atleta de Ouro, [...] tem por finalidade treinar e capacitar as crianças do $1^{\circ}$ ao $5^{\circ}$ ano em uma escolinha voluntária de futebol e handebol no contra-turno do horário escolar. Com isso, as crianças não ficam ociosas pelas ruas, têm o compromisso de se portarem bem dentro da escola e de terem bom desempenho cognitivo (P93); Coral; Orquestra de Violões em parceria Sedu e Faculdade de Música do Espírito Santo (Fames) (P 95);

Aulas de Geografia nas matas da própria região, nas reservas e nos demais ambientes naturais. Aulas de Matemática no supermercado do bairro e de Português por meio de exploração de temas que são comuns nas famílias atendidas (P129).

O programa Mais Educação é considerado pela escola como uma forma importante de manter relação com o seu entorno.

Mais Educação foi extremamente importante para o CMEA nesses dois anos em que conseguiram fazer a adesão, pois, obtiveram resultados surpreendentes, uma vez que puderam ofertar no contra turno aulas de Reforço Escolar, Música (violão), Teatro e Educação Ambiental (P81).

Mais Educação na escola tivemos um dos melhores anos, pois os alunos estavam inseridos em trabalhos que faziam parte de sua vida como por exemplo a oficina de horta que eles plantavam e colhiam, e o mais importante que os oficineiros eram moradores da comunidade que transmitiam seu conhecimento a respeito do que eles sabiam (P71).

Com esse programa, a escola vai até os espaços externos dos territórios, não para se relacionar e aprender com ele, mas para que a aula ocorra em um ambiente externo. Não há evidências de que os projetos realizados partiram de um diálogo e das necessidades desses sujeitos, voltados à resistência e superação da pobreza. Observamos, portanto, planejamento de projetos, com dias marcados para começar e para acabar, desconsiderando, por sua vez, um planejamento de processos, tendo os territórios como 
principal meio de estudos e aprendizagem.

O programa Escola Aberta do Governo Federal foi criado pela Resolução CD/FNDE no 052/2004, com a finalidade de fomentar ações para promover a melhoria da qualidade da educação por meio do envolvimento e da participação da comunidade, ampliando o diálogo e a cooperação entre alunos, pais e equipes profissionais que atuam nas escolas. Trata-se, pois, de um programa orientado para funcionar com atividades nos finais de semana e voltado para a comunidade. Os recursos são repassados de acordo com o número de pessoas matriculadas. Apresentamos, a seguir, um relato que considera as atividades da Escola Aberta como forma da existência da relação escola e território: "Com o intuito de fortalecer a relação com a comunidade, foi implementado na escola o Projeto Escola Aberta, onde todos os finais de semanas adolescentes e jovens de várias idades procuram a escola para participar de programas esportivos" (P138). Ressaltam os professores que esse projeto possibilitava a escola permanecer aberta e disponível durante 0 sábado e o domingo com realização de várias oficinas e atividades culturais para a comunidade.

O Programa Educacional de Resistência às Drogas (Proerd), desenvolvido nas escolas pesquisadas, originou-se do Drug Abuse ResistenceEducation (DARE), programa norte-americano, que foi adaptado e implementado no Brasil em 1992, pela Polícia Militar. O seu currículo é organizado para atuar na Educação Infantil e no Ensino Fundamental. Além de ações para os estudantes, há também ações direcionadas aos pais. 0 Proerd funciona nas escolas do Espírito Santo há mais de 15 anos em parceria com a Secretaria Estadual de Educação e Secretarias Municipais, tendo por referência os objetivos abaixo descritos:

A Polícia Militar ministrou o Projeto Proerd para as crianças dos Grupos 6, que dentre os principais objetivos estão os de: ter maior proximidade com a comunidade, prevenir a criminalidade relacionada direta ou indiretamente ao uso de drogas, sensibilizar as crianças para valores morais e éticos visando a construção de uma sociedade mais justa, sadia e feliz, etc. (P234).

Ressaltamos que esses programas pontuais nas escolas emergem por consequência do encolhimento do Estado, que, desde 1990, tem se pautado na racionalidade financeira quando pensado na prestação de serviços públicos essenciais à sociedade, com graves consequências na área de educação. Krawczyk (2005) analisa que o texto da LDB (Lei N. 9394/96) restringe os direitos consagrados na Constituição de 1988 na medida em que reformula as responsabilidades e atribuições do Estado, do mercado e da sociedade no âmbito educativo, permitindo tornar a educação formal brasileira compatível com as reformas modernizantes de Estado.

Segundo a autora, nessa reforma foram transferidas funções e responsabilidades para a comunidade por meio do envolvimento privado e voluntário no funcionamento e na gestão da escola. Essa gestão é avaliada mediante sua capacidade e autossuficiência institucional de formular as próp rias demandas, produzir e gerir os recursos para satisfazêlas, incluindo, nessa competência gerencial, os atos de filantropia, pois "as propostas nesse sentido incentivam a ideia de que a responsabilidade pela educação e pelo bemestar deve ser assumida por todos, e não ficar relegada ao Estado [...]" (KRAWCZYK, 2005, p. 813). 
Assim, os programas criados por força dessa nova política trazem em si um paradoxo que merece destaque. Essas políticas, ao mesmo tempo que afirmam a educação como promotora da igualdade, do desenvolvimento econômico e, portanto, capaz de libertar os pobres de sua condição de pobreza, desmobilizam os sujeitos da possibilidade de exercitar suas cidadanias, deixando de cobrar do Estado o que lhes é devido e, com isso, a desigualdade social passa a ser algo natural que faz parte da vida cotidiana das pessoas.

\section{RELAÇÃO ESCOLA E TERRITÓRIO: EMPECILHOS APONTADOS}

As escolas pesquisadas possuem estruturas físicas com muros e grades que as separam de seus territórios. Os lugares em que essas escolas estão inseridas são vistos como perigosos e as crianças que ficam nas ruas para brincar são consideradas em situação de risco social. Nesse sentido, as famílias veem as escolas como uma proteção para as crianças e jovens pelo fato de tirá-las das ruas, pelo menos por um período. 0 território é como um espaço a ser evitado. Desse modo, não se demarcam os territórios pelas muitas possibilidades educativas que ele apresenta. Com isso, o programa Mais Educação teve boa aceitação nessas escolas, porque era uma forma de tirar as crianças das ruas.

0 principal fator apontado por algumas escolas para não ter nenhum tipo de relação com o território é a violência, pois "na comunidade não há espaços para a participação escolar, por apresentar perigo aos alunos e funcionários" (P239). São muitos os relatos dessa natureza em que o território é visto como algo perigoso, violento e, por isso, deve ser evitado. A escola, então, se reconfigura e torna-se abrigo seguro, até porque separar os alunos de seus contextos de vida faz com que as crianças e os jovens aprendem uma triste lição de que os seus territórios são lugares perigosos, habitados por drogados, bandidos etc. Essa demarcação negativa dos territórios pela escola não contribui com o desenvolvimento deles e não se abre às possibilidades de ensino e de aprendizagem nesses espaços. É fundamental aprender na escola a olhar para esses espaços, enxergar as contradições sociais e vislumbrar formas de superação, pois esse é o princípio básico do exercício da cidadania e, por conseguinte, de resistência e superação da pobreza.

Esse olhar para o território como um lugar perigoso, cabendo à escola o papel de retirar as crianças e jovens de lá, representa, segundo Arroyo (2011), uma forma explícita de reprodução da desigualdade, visto que, na perspectiva do autor, na segregação de determinados sujeitos, "[...] está a perversa relação política de inferiorização racial que acompanha nossa história, que o campo do conhecimento e da cultura, da escola reproduz: as tentativas de manter os coletivos étino-raciais como invisíveis, à margem" (ARROYO, 2011, p. 141).

Além da questão da violência, foi observado também que algumas escolas não veem objetivo nem necessidade de manter uma relação com a comunidade, uma vez que ela se reconhece como uma cultura superior, cabendo a essas pessoas se apropriar dessa cultura para se redimirem da pobreza. Como justificativa, apontam o desinteresse da própria comunidade; do diretor que não permite a presença da comunidade na escola e, 
também, a resistência por parte dos professores, entre outras.

\section{CONSIDERAÇÕES FINAIS}

O presente estudo revelou que as formas de relação que as escolas estabelecem com os seus territórios se realizam por força de programas governamentais, criados por força da política de redução do tamanho do Estado que trazem em si um paradoxo que merece destaque: propõem-se a investir no desenvolvimento econômico e na melhoria das condições educativas do povo, mas o que acabam promovendo, de fato, é a desmobilização dos sujeitos e a criação de condições desfavoráveis ao exercício da cidadania. Isso leva os sujeitos pobres a ser responsáveis por resolver as questões que são da ordem do Estado. Trata, pois, de uma cidadania invertida em que os sujeitos tomam, para si, a tarefa individual de superar as suas condições de pobreza.

A escola, nessa perspectiva, invisibiliza o mundo dos estudantes e cria para eles um mundo à parte. Isso acontece por aquela desvincular o ensino da realidade concreta de seus sujeitos. Portanto, trata-se de uma educação desvinculada do lugar em que vivem os estudantes, ou seja, das suas práticas sociais, suas culturas, suas histórias, suas lutas e da relação intrínsecas com as questões da realidade mais ampla. Desse modo, a concepção de escola e de educação não é pensada como parte dos processos formativos que constituem a vida social e as relações entre ser humano e a natureza numa direção emancipatória.

Artigo recebido em: 31/10/2018 Aprovado para publicação em: 18/12/2018

\section{THE SCHOOL AS TIME/SPACE OF RESISTANCE AND INEQUALITIES RESILIENCE: THE RELATION WITH TERRITORIES}

ABSTRACT: The article specifies the analyses and discussions developed concerning as theme the school: space and time of reproduction and poverty resistance,focusing on the school relation with its own territory, carried out with the purpose of identifying how schools relate with their impoverished territories and analyzing those relations implications regarding the production of resistance and poverty resilience/overcoming. The work used a qualitative research based on the dialectical method. It highlighted that the schools do not develop an effective relation with their territories in order to acknowledge them as important spaces for education and life production.

KEYWORDS: Territory. Poverty. Emancipatory education. School.

\section{LA ESCUELA COMO TIEMPO/ESPACIO DE RESISTENCIA Y SUPERACIÓN DE LAS DESIGUALDADES: LA RELACIÓN CON LOS TERRITORIOS}

RESUMEN: Este artículo especifica los análisis y las discusiones llevados a cabo en la temática escuela: espacios y tiempos de reproducción y resistencias de la pobreza, enfocando la relación de la escuela con su territorio, realizados con el objetivo de identificar cómo la escuela se relaciona con 
sus territorios empobrecidos, así como, analizar las implicaciones de dicha relación para la producción de resistencia y de la superación de la pobreza. Adoptó una investigación cualitativa basada en el método dialéctico. Evidenció que las escuelas no desarrollan una relación afectiva con sus territorios en el reconocimiento de estos como espacios importantes de aprendizaje y de producción de vida.

PALABRAS CLAVE: Territorio. Pobreza. Educación emancipadora. Escuela.

\section{REFERÊNCIAS}

ARROYO, M. G. Pedagogias em movimento: 0 que temos a aprender dos movimentos sociais. Currículo sem Fronteiras, Belo Horizonte, UFMG, v. 3, n.1 p.28-49, jan. jun. 2003.

ARROYO, M. G. Currículo, território em disputa. Petrópolis: Vozes, 2011.

ARROYO, M. G. Pobreza e currículo:uma complexa articulação - Módulo IV. Brasil, 2015.

BRASIL. Ministério da Educação. Secretaria de Educação Continuada, Alfabetização e Diversidade. Diretoria de Educação Integral, Direitos Humanos e Cidadania. Programa Mais Educação Passo a Passo. Brasília: Ministério da Educação. Secretaria de Educação Continuada, Alfabetização e Diversidade, 2014.

BRASIL. Ministério da Educação. Secretaria de Educação Continuada, Alfabetização e Diversidade. Instituto Nacional de Estudos e Pesquisas Educacionais Anísio Teixeira. Censo Escolar da Educação Básica 2013: resumo técnico. Brasília: Instituto Nacional de Estudos e Pesquisas Educacionais Anísio Teixeira, 2014.

CALDART, R. S.; PALUDO, C.; DOLL, J. (Org.). Como se formam os sujeitos do campo? Idosos, adultos, jovens, crianças e educadores. Brasília: Pronera; Nead, 2006.

FREIRE, P. Pedagogia da autonomia: saberes necessários à prática educativa. 43. ed. São Paulo: Ed. Paz e Terra, 2011.

FREIRE, P. Pedagogia do oprimido. 17. ed. Rio de J aneiro: Paz e Terra, 2005.

MÉSZÁROS, I. A educação para além do capital. São Paulo: Boitempo, 2005.

MOVIMENTO SEM-TERRA (MST). Cartilha de estudos organicidade e planejamento. São Paulo: MST, 2004. 
ORGANIZAÇÃO DAS NAÇÕES UNIDAS (ONU). Organização das Nações Unidas para a Alimentação e Agricultura (FAO). A superação da fome e da pobreza rural: iniciativas brasileiras. Brasília: ONU/FAO, 2016.

SALAMA, P.; DESTREMAU, B. O tamanho da pobreza:economia política da distribuição de renda. Rio de J aneiro: Garamond, 1999.

SANTOS, M. A natureza do espaço: técnica e tempo. São Paulo: Hucitec, 1996.

YANNOULAS, S. C. Política educacional e pobreza: múltiplas abordagens para uma relação multideterminada. Brasília: Liber Livro, 2013.

DulCinÉa Campos: Professora Doutora do Centro de Educação na Graduação e PósGraduação em Educação, da linha de pesquisa Práticas Educativas, Diversidade e Inclusão Escolar, da Universidade Federal do Espírito Santo.

E-mail: dulcampos@smail.com

Itamar Mendes da Silva: Professor Associado do Centro de Educação na graduação e pós-graduação em Educação, Docência e Gestão de Processos Educativos da Universidade Federal do Espírito Santo.

E-mail: itamar.mendes@ufes.br

Caroline Falco Fernandes Valpassos: Pós-Doutoranda em Política Social na Universidade de Brasília (UNB).

E-mail: cacauvalpassos@gmail.com

Este periódico utiliza a licença Creative Commons Attribution 3.0, para periódicos de acesso aberto (Open Archives Iniciative - OAI). 